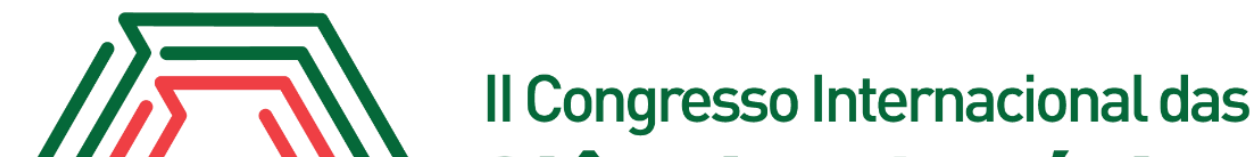 Ciências Agrárias COINTER - PDVAgro 2017
}

\section{AVALIAÇÃO DO POTENCIAL ADSORVENTE DA BIOMASSA DE COCO VERDE QUANTO À REDUÇÃO DA SALINIDADE EM ÁGUA PRODUZIDA}

\author{
Apresentação: Pôster \\ Ana Júlia Miranda de Souza ${ }^{1}$; Carliane Ileicy da Silva ${ }^{2}$; Luiz Antônio Barbalho Bisneto ${ }^{3}$; \\ Tatiane Pinheiro da Silva ${ }^{4}$; Fabiola Gomes de Carvalho ${ }^{5}$
}

\section{Introdução}

Dentre os resíduos derivados da extração do petróleo está a água produzida (AP), que é composta por diversos compostos químicos nocivos ao meio ambiente, destacando-se sua alta salinidade. A sua complexa e tóxica composição é determinante na escolha dos processos de tratamento e no seu respectivo local de descarte.

Para o tratamento da AP destaca-se como tecnologia inovadora a adsorção biológica, tendo fibras naturais como material biossorvente. Por ser um material de baixo custo, abundante e por apresentar efetiva capacidade adsorvente, a fibra de coco verde vem despertando grande interesse em estudos de biossorção. Nesse contexto, o objetivo deste estudo foi avaliar o potencial adsorvente da biomassa de coco verde quanto à redução da salinidade em água produzida.

\section{Fundamentação Teórica}

A água produzida (AP) é um efluente gerado durante o processo da extração de petróleo e apresenta diversos compostos químicos danosos ao meio ambiente, incluindo metais pesados $(\mathrm{Cd}$, $\mathrm{Pb}, \mathrm{Cr}, \mathrm{Ni}$, etc.), óleo e elevada salinidade. A alta salinidade presente na AP, que em alguns casos pode supera até mesmo a do mar é nociva ao meio ambiente, podendo impactar sobre os mananciais de água doce destinados à agricultura e ao consumo humano. A complexa composição e elevada concentração de componentes tóxicos presentes na AP são determinantes na escolha dos processos

\footnotetext{
${ }^{1}$ Tecnologia em Gestão Ambiental, IFRN - Campus Natal Central, anajuliamds21@gmail.com

2 Tecnologia em Gestão Ambiental, IFRN - Campus Natal Central, carlianeturismo@yahoo.com.br

${ }^{3}$ Tecnologia em Gestão Ambiental, IFRN - Campus Natal Central, luiz.tangara@gmail.com

${ }^{4}$ Tecnologia em Gestão Ambiental, IFRN - Campus Natal Central, tatiane.pinheiropp@gmail.com

${ }^{5}$ Doutora, IFRN - Campus Natal Central, fabiola.carvalho@ifrn.edu.br
} 
de tratamento deste efluente e no seu respectivo local de descarte (CARVALHO, 2011; NUNES, 2009).

Dentre as tecnologias para o tratamento da AP estão a hidrociclone, que utiliza um campo centrífugo para separação, a flotação, que separa as partículas sólidas ou óleos e graxas de uma fase líquida, o POA's (processos oxidativos avançados), que utilizam a radiação UV e reação radicalar, e a adsorção biológica, fenômeno físico-químico onde suas moléculas acumulam-se sobre a superfície do biossorvente de maneira natural, eficientes, além do baixo custo. (SOUSA, 2013; PINO, 2005).

O coqueiro, Cocos nucifera L., é uma das frutíferas mais difundidas naturalmente no planeta, sendo o Brasil é o seu quarto maior produtor, merecendo destaque sua utilização agroindustrial e uso in natura do coco verde. O descarte de sua casca tem se tornado um problema ambiental devido a ser um resíduo volumoso e de difícil degradação, levando mais de oito anos para se decompor (MARTINS \& JESUS, 2011).

A biomassa derivada do coco verde surge como uma oportunidade econômica e estratégica para o desenvolvimento de tecnologias inovadoras no processo de descontaminação de efluentes industriais pelo método de adsorção, que é a capacidade de um sólido em reter em sua superfície moléculas ou íons de um fluido (SILVA et al., 2013; FERREIRA et al., 2014).

\section{Metodologia}

Esta pesquisa científica caracterizou-se como experimental, pois baseou-se na escolha de um objeto de estudo, na determinação das variáveis que poderiam influenciá-lo e na análise dos efeitos que a variáveis produziram no objeto (GIL, 2002). Os experimentos foram realizados nos laboratórios de Análise de Solos e Resíduos Sólidos e de Físico-química do IFRN - CNAT.

Para obtenção da biomassa de coco verde seguiu-se o modelo de secagem de Rosa et al., (2001), de acordo com o fluxograma 1:

Fluxograma 1: Etapas para obtenção da biomassa de coco verde. Fonte: Embrapa (2001)

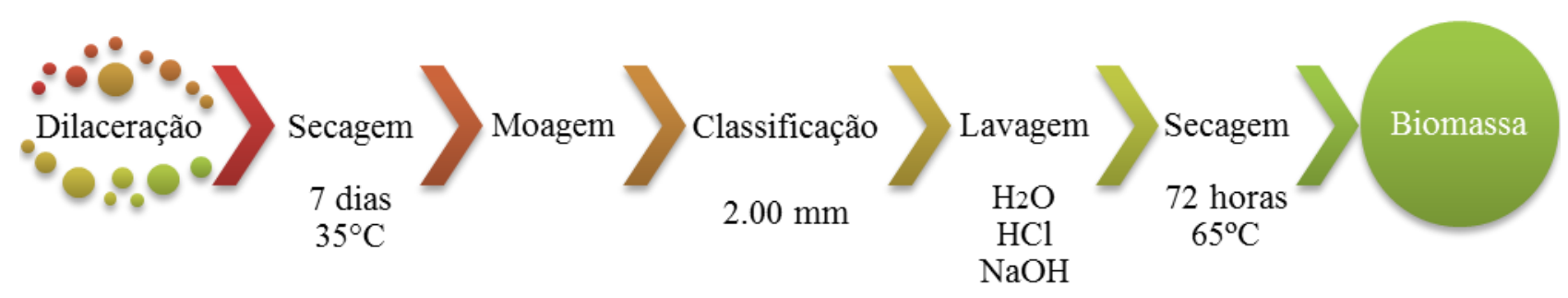


No estudo da adsorção dos íons de sódio $(\mathrm{Na})$ e potássio $(\mathrm{K})$ em AP foram avaliados a influência do pH e a cinética de adsorção dos mesmos, variável de acordo com o tempo de contato de 20, 40 e 60 minutos. Os ensaios foram realizados com cinco repetições, na proporção 1:60 (1g de fibra para $60 \mathrm{~mL}$ de AP). Todos os testes foram submetidos a agitação horizontal com velocidade constante de $150 \mathrm{rpm}$.

Após o processo de adsorção, as amostras foram filtradas, sendo analisados o $\mathrm{pH}$, a condutividade elétrica (CE) e os teores de Na e K trocáveis, segundo a metodologia de Silva (1999). A porcentagem adsorvida foi determinada pela equação 1, que estabelece uma relação entre as concentrações iniciais $(\mathrm{Ci})$ e as concentrações finais do efluente $(\mathrm{Cf})$ :

$$
\% \text { adsorvido }=(\mathrm{Cf} \times 100) / \mathrm{Ci}
$$

O teste de fitotoxicidade, adaptado de Lins (2005), analisou os lixiviados de AP, quanto a possíveis riscos ambientais através da germinação de sementes de alface (Lactuca sativa). Visto que, quando utilizada em reuso na irrigação, a AP devido as suas altas concentrações de sais e metais pesados, pode causar problemas na germinação das sementes, na planta jovem, na maturação, no crescimento da raiz e nos ramos (CARVALHO, 2011; LINS, 2005).

\section{Resultados e Discussões}

A caracterização das biomassas adsorventes e da $\mathrm{AP}$, em relação ao $\mathrm{pH}$ e a $\mathrm{CE}$ estabeleceu que a fibra sem tratamento possuía pH 5,3 e após as lavagens alterou-se para 4,8; 3,8 e 5,7 respectivamente para os tratamentos com $\mathrm{H}_{2} \mathrm{O}, \mathrm{HCl}$ e $\mathrm{NaOH}$, enquanto o $\mathrm{pH}$ da AP foi de 6,4. Já a CE que inicialmente era de $76,8 \mu \mathrm{S} / \mathrm{cm}^{-1}$ na fibra sem tratamento, passou a 81,5; 102,6 e 86,86 $\mu \mathrm{S} / \mathrm{cm}^{-1}$ após as lavagens com $\mathrm{H}_{2} \mathrm{O}, \mathrm{HCl}$ e $\mathrm{NaOH}$, enquanto a $\mathrm{CE}$ da $\mathrm{AP}$ apresentou-se extremamente elevada $1777 \mu \mathrm{S} / \mathrm{cm}^{-1}$, o esperado devido a sua característica salina.

Devido ao $\mathrm{pH}$ ácido das biomassas e consequentemente maior disponibilidade de íons $\mathrm{H}^{+}$, tornou-se possível alterar o pH da AP a partir do método de biossorção (Tabela 1). Houve redução da CE entre 59 e $68 \%$, independente do tratamento e variações de tempo testadas. 
Tabela 1: pH, CE, Na, K e porcentagens de remoção nos lixiviados de água produzida. Fonte: Própria

\begin{tabular}{|c|c|c|c|c|c|c|c|c|}
\hline & \multirow{2}{*}{$\begin{array}{c}\Delta \mathrm{t} \\
(\mathrm{min})\end{array}$} & \multirow{2}{*}{$\mathrm{pH}$} & \multicolumn{2}{|c|}{$\mathrm{CE}$} & \multicolumn{2}{|c|}{$\mathrm{Na}$} & \multicolumn{2}{|c|}{$\mathrm{K}$} \\
\hline & & & $\mu \mathrm{S} . \mathrm{cm}^{-1}$ & Redução & $\mathrm{ppm}$ & Redução & $\mathrm{ppm}$ & Redução \\
\hline AP & & 6,40 & 1777,0 & & 60 & & 87 & \\
\hline \multirow{3}{*}{$\mathrm{H} 2 \mathrm{O}$} & 20 & 6,33 & 703,4 & $60 \%$ & 29 & $52 \%$ & 32 & $64 \%$ \\
\hline & 40 & 6,65 & 569,2 & $68 \%$ & 30 & $50 \%$ & 33 & $62 \%$ \\
\hline & 60 & 6,67 & 777,8 & $56 \%$ & 30 & $50 \%$ & 34 & $61 \%$ \\
\hline \multirow{3}{*}{$\mathrm{HCl}$} & 20 & 5,91 & 563,5 & $68 \%$ & 31 & $48 \%$ & 35 & $60 \%$ \\
\hline & 40 & 6,01 & 683,6 & $62 \%$ & 31 & $48 \%$ & 35 & $59 \%$ \\
\hline & 60 & 6,24 & 742,4 & $58 \%$ & 32 & $47 \%$ & 35 & $59 \%$ \\
\hline \multirow{3}{*}{$\mathrm{NaOH}$} & 20 & 7,32 & 721,7 & $59 \%$ & 32 & $46 \%$ & 35 & $59 \%$ \\
\hline & 40 & 7,27 & 675,2 & $62 \%$ & 33 & $46 \%$ & 36 & $59 \%$ \\
\hline & 60 & 7,22 & 576,2 & $68 \%$ & 30 & $49 \%$ & 33 & $62 \%$ \\
\hline
\end{tabular}

Em relação aos teores de Na e K trocável também foram observadas significativas reduções neste parâmetro em todos os tratamentos de biossorção avaliados, sendo mais representativa a remoção de $\mathrm{Na}$ na fibra $\mathrm{H}_{2} \mathrm{O}$ em todas as variações de tempo. Em valores percentuais as reduções de $\mathrm{Na}$ foram em média de $47 \%$ para fibra com $\mathrm{NaOH}, 48 \%$ para fibra com $\mathrm{HCl}$ e de $51 \%$ para as fibras com $\mathrm{H}_{2} \mathrm{O}$. As remoções de $\mathrm{K}$ foram mais expressivas que as de $\mathrm{Na}$, atingindo em média: $63 \%$ $\left(\mathrm{H}_{2} \mathrm{O}\right), 61 \%(\mathrm{NaOH})$ e $59 \%(\mathrm{HCl})$. Dessa forma, destaca-se que o processo de biossorção para AP mostrou-se efetivo quanto à remoção de íons Na e K.

Nos ensaios de fitotoxicidade com sementes de alface e os lixiviados de AP, demonstrou que os mesmos foram fitotóxicos, pois houve total inibição da germinação das amostras submetidas ao contato direto com os lixiviados sem diluição, enquanto nas amostras de controle regadas com água destilada apresentaram 100\% de germinação.

\section{Conclusões}

O processo de biossorção para água produzida tendo o pó de casca de coco verde como adsorvente, apresentou-se eficaz, sobretudo, quanto ao potencial de redução da salinidade e adsorção de elementos como Na e K.

Nos resultados de fitotoxicidade ficou evidente que a toxidade ainda esteve presente na água produzida adsorvida, uma vez que houve severa inibição da germinação das sementes de alface submetidas ao contato direto com os lixiviados sem diluição.

$\mathrm{O}$ avanço nas pesquisas com tecnologias direcionadas a reciclagem de agroresíduos e 
tratamento de efluentes industriais é importante, porque, além de reduzir a quantidade de resíduos destinados aos aterros sanitários e/ou descarte indevido, contribui para uma gestão ambiental sustentável, englobando aspectos sociais, econômicos e sobretudo, ambientais.

\section{Referências}

CARVALHO, P. C. A. P. Caracterização de água produzida na indústria de petróleo para fins de descarte e otimização do processo de separação óleo/água. 2011. 122 f. Dissertação (Mestrado em Engenharia Química) - Universidade Federal do Rio Grande do Norte, 2011.

FERREIRA A. M.; SILVA G. C.; DUARTE H. A. Materiais Funcionais para a Proteção Ambiental. Cadernos Temáticos de Química Nova na Escola, N 8, p. 30-38, MAIO 2014.

GIL, A.C. Métodos e técnicas de pesquisa social. São Paulo: Atlas, 2002.

LINS, M. C. M. Avaliação microbiológica e fitotóxica do chorume da estação de tratamento do aterro da Muribeca - PE. 2005. 91 f. Dissertação (Mestrado em Biotecnologia de Produtos Bioativos) - Universidade Federal de Pernambuco, Recife, PE, 2005.

MARTINS, C. R; JESUS JR, L. A. Evolução da produção de coco no Brasil e o comércio internacional: panorama 2010. Embrapa Tabuleiros Costeiros. Aracaju, SE. Doc. 164. 28 p. 2011.

NUNES, S. K. S. Remoção conjugada de metais e óleo de água produzida. 2009. $108 \mathrm{f}$. Dissertação (Mestrado em Engenharia Química) - Universidade Federal do Rio Grande do Norte, 2009.

PINO, G. A. H. Biossorção de metais pesados utilizando pó da casca de coco verde (Cocos nucifera). 2005. 113 f. Dissertação (Mestrado em Engenharia Metalúrgica e de Materiais) Pontifícia Universidade Católica do Rio de Janeiro, 2005.

ROSA, M. F.; SANTOS, F. J. S.; MONTENEGRO, A. A. T.; ABREU, F. A. P.; CORREIA, D.; ARAUJO, F. B. S.; NOROES, E. R. V; Comunicado Técnico, Nº 54; Caracterização do pó da casca de coco verde usado como substrato agrícola. EMBRAPA: Fortaleza, p. 1-6, mai. 2001.

SILVA, F.C. (Org.). Manual de análises químicas de solos, plantas e fertilizantes. Brasília: Embrapa; Rio de Janeiro: Embrapa Solos; Campinas: Embrapa Informática Agropecuária, 1999. 370 p.

SILVA, N. A. FERREIRA, D. C.; LIMA, A. F. Absorção de metais tóxicos pelas fibras de Cocos nucifera L. Centro Científico Conhecer: Enciclopédia Biosfera, Goiânia, GO, v. 9, n. 16, p. 2778-2786, 01 jul. 2013.

SOUSA, M. A. S. B. Águas Produzidas DE PETróleO: origem e técnicas de tratamento. 2013. Disponível em: <https://goo.gl/VxXQhw>. Acesso em: 25 jun. 2017. 